\title{
Capsule Commentary on Lee et al., Telemonitoring and Team-Based Management of Glycemic Control on People with Type 2 Diabetes: a Cluster Randomized Controlled Trial
}

\author{
Shira $H$. Fischer, MD, PhD \\ RAND Corporation, Boston, USA. \\ $\mathrm{J}$ Gen Intern Med 35(1):402 \\ DOI: $10.1007 / \mathrm{s} 11606-019-05493-7$ \\ (c) Society of General Internal Medicine 2019
}

$\mathrm{L}$ ee and colleagues tested the impact on glycemic control of a remote telemonitoring intervention with team-based management for diabetes. ${ }^{1}$ They found no effect of this intervention. While a negative finding is disappointing, given prior evidence of the power of telemedicine, this finding can also be informative, as it emphasizes that it is not enough to add technology to the equation but rather it has to be designed and implemented to have a measurable effect.

Moreover, this research heeds the calls for increased publication of negative findings. ${ }^{2,3}$ In his 2005 paper, "Why most published research findings are false," John Ioannidis makes a compelling argument that-with too much focus on $p$ values and with too many comparisons in a study - "for most study designs and settings, it is more likely for a research claim to be false than true." 2 Too many studies make a claim based on a small sample with a $p$ value just shy of 0.05 - findings which often aren't replicated.

Thus while Lee et al.'s finding of lack of impact on HbA1C might be disappointing, the reporting of the negative finding contributes to the ongoing attempt to figure out how to incorporate technology as an effective tool. This may require better educating patients and families; ensuring access to the Internet or to technical support; increasing follow-up and reminders; or other structural issues, particularly in this unique setting. Indeed, Lee et al. note that, "While various reviews and metaanalyses have suggested that telemedicine can potentially

improve glycemic control, this could be due to the ideal research setting compared to the pragmatic design in this study." 1 For that reason, this kind of research is important; it is helpful to know what is possible in a clinical trial, but ultimately what clinicians need to know is how to effectively implement creative solutions in real life. It would also have helped to separate out the telemonitoring from coaching to allow evaluation of each. Moreover, the application of these kinds of tools in lower-resource settings in realistic contexts is where the real greatest benefit could be seen, thus that is where they should be tested.

Corresponding Author: Shira H. Fischer, MD, PhD; RAND Corporation, Boston, USA (e-mail: sfischer@rand.org).

\section{Compliance with Ethical Standards:}

Conflict of Interest: The author declares that she does not have a conflict of interest.

\section{REFERENCES}

1. Lee JY, Chan CKY, Chua SS, Ng CJ, Paraidathathu T, Lee KKC, et al. Telemonitoring and Team-based Management of Glycemic Control on People with Type 2 Diabetes: A Cluster Randomized Controlled Trial. JGIM. 2019. https://doi.org/10.1007/s11606-019-05316-9

2. Ioannidis JP. Why most published research findings are false. PLoS medicine. 2005;2(8):e124.

3. Boorman GA, Foster JR, Laast VA, Francke S. Regulatory Forum Opinion Piece* The Value of Publishing Negative Scientific Study Data. Toxicologic pathology. 2015;43(7):901-6.

Publisher's Note Springer Nature remains neutral with regard to jurisdictional claims in published maps and institutional affiliations.

Published online October 25, 2019 